\title{
Posterior fossa decompression with duraplasty in Chiari surgery: A technical note
}

\author{
Marcelo Ferreira Sabba ${ }^{1}$, Beatriz Souza Renor ${ }^{1}$, Enrico GhizonI ${ }^{2}$, Helder Tedeschl² ${ }^{2}$ Andrel Fernandes Joaquim ${ }^{3 *}$ \\ ${ }^{1} \mathrm{MD}$. Neurosurgery Resident, Universidade Estadual de Campinas (Unicamp), Campinas, SP, Brazil \\ ${ }^{2} \mathrm{MD}$, PhD. Professor of Neurosurgery, Unicamp, Campinas, SP, Brazil \\ ${ }^{3} \mathrm{MD}$, PhD. Neurosurgeon, Unicamp, Campinas, SP, Brazil
}

Study conducted at Universidade Estadual de Campinas (Unicamp), Campinas, SP, Brazil

Article received: 4/2/2017 Accepted for publication: 4/3/2017

*Correspondence:

Departamento de Neurologia Hospital das Clínicas da Faculdade de Medicina da Universidade de Campinas Cidade Universitária Zeferino Vaz Campinas, SP - Brazil Postal code: $13083-888$ andjoaquim@yahoo.com

http://dx.doi.org/10.1590/1806-9282.63.11.946

\section{SUMmARY}

Chiari malformation (CM) is the most common and prevalent symptomatic congenital craniocervical malformation. Radiological diagnosis is established when the cerebellar tonsils are located $5 \mathrm{~mm}$ or more below the level of the foramen magnum on magnetic resonance imaging (MRI). Surgical treatment is indicated whenever there is symptomatic tonsillar herniation or syringomyelia/ hydrocephalus. The main surgical treatment for CM without craniocervical instability (such as atlantoaxial luxation) is posterior fossa decompression, with or without duraplasty. The authors describe in details and in a stepwise fashion the surgical approach of patients with CM as performed at the State University of Campinas, emphasizing technical nuances for minimizing the risks of the procedure and potentially improving patient outcome.

Keywords: Arnold-Chiari malformation/surgery, cerebellum/pathology, neural tube defects.

\section{INTRODUCTION}

Chiari malformation (CM) was described in 1891 by Hans Chiari as a caudal displacement of the cerebellar tonsils through the foramen magnum. ${ }^{1}$ The prevalence of patients with CM in the US is estimated at about 215,000 individuals, ${ }^{2}$ being the most common and prevalent symptomatic congenital craniocervical malformation..$^{2-4}$ Type 1 $\mathrm{CM}$, diagnosed when the cerebellar tonsils are located 5 $\mathrm{mm}$ or more below the level of the foramen magnum on magnetic resonance imaging (MRI), is the commonest form and is discussed in the present article. ${ }^{5}$ This radiological diagnosis is questioned by many authors, once the amount of herniation needed to be considered as "abnormal" and to produce clinical symptoms is extremely variable (some patients may present with symptoms with less herniation and others may even be asymptomatic). ${ }^{6}$ Tonsillar herniation, associated with a small posterior fossa volume, may result in cerebrospinal fluid (CSF) flow abnormalities and in upper cervical spine and brainstem compression, leading to a constellation of clinical symptoms. ${ }^{7,8}$

Surgical treatment is indicated whenever there is symptomatic tonsillar herniation or syringomyelia/hydrocephalus. The main surgical treatment for $\mathrm{CM}$ without craniocervical instability (such as atlantoaxial luxation) is posterior fossa decompression, with or without duraplasty. The benefits of posterior fossa decompression in patient outcome are well established in many case series. ${ }^{9-13}$

The present technical note describes in details and in a stepwise fashion the surgical approach of patients with $\mathrm{CM}$ as it is done at our institution (State University of Campinas). The rationale of each step is discussed along with a review of the pertinent literature.

\section{SURGICAL TECHNIQUE}

Patient position

After general anesthesia, the patient is positioned prone on the operating table and cushioned with chest rolls. Central venous access is usually not necessary. The neck is flexed in order to expose the posterior fossa, and the foramen magnum and the head are fixed with a head holder. In order to facilitate venous return and avoid excessive bleeding we generally flex the neck only up to a point where we are sure there is no compression of the jugular veins (Figure 1A).

It is of paramount importance to exclude atlantoaxial instability or cranial settling and basilar invagination prior to positioning, once flexion in these patients may result in ventral brainstem or upper cervical spinal cord compres- 


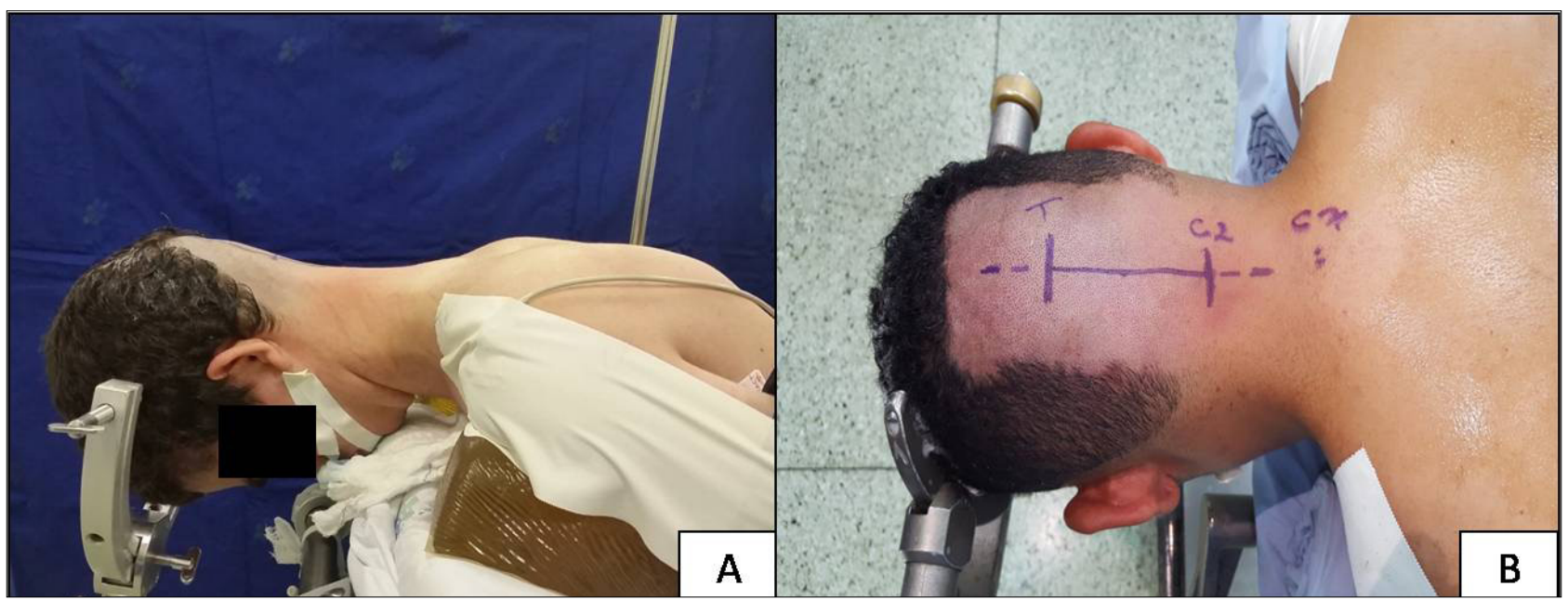

FIGURE 1 A. Lateral view of the patient position. The neck is flexed but not too much, as to avoid jugular compression. B. The incision goes from $3 \mathrm{~cm}$ above the inion ( $T$-torcula) to the $\mathrm{C} 2$ prominence in the skin.

sion. ${ }^{14-16}$ A dynamic CT scan or MRI is recommended to exclude instability. In such cases, we recommend neurophysiologic monitoring with motor and somatosensory evoked potentials. A neutral position is preferred in such cases and mandatory if craniocervical fixation is planned.

\section{Skin incision, dissection and bone exposure}

A midline skin incision is started about $3 \mathrm{~cm}$ above the inion down to the skin prominence of the $\mathrm{C} 2$ spinous process (Figure 1B). The cranial extension of the skin incision is used for harvesting a pericranial graft for the duroplasty. ${ }^{17}$ We favor the use of pericranium instead of artificial grafts because it avoids foreign body reaction and potentially decreases the risks for infection and the chances of further arachnoiditis, which may be the cause of Chiari reoperations. ${ }^{18}$ The graft is preferentially harvested before opening the dura in order to avoid bleeding into the subarachnoid space.

The fascia is exposed and then opened in a " $\mathrm{T}$ " fashion using monopolar cautery (Figure 2). The transverse portion of the "T"-shaped incision is made about 0.5 to $1 \mathrm{~cm}$ below the insertion of the muscles in the superior nuchal line. We preserve the muscle attachment in the superior nuchal line so as to allow for the suture of the paraspinous muscles back in place at the end of the procedure. This may preserve function and avoid CSF leak while providing a tight and hermetic closure. The longitudinal incision is made from the transverse incision down toward the posterior tubercle of the atlas (C1) in the midline. Maintaining the incision in the midline, which is practically avascular, potentially decreases postoperative pain and avoids muscle injury. We open the midline with monopolar cautery and then apply self-retaining retractors to separate the paraspinous musculature. The posterior part of the $\mathrm{C} 1$ arch is then exposed about $2 \mathrm{~cm}$ laterally on each side of the posterior tubercle of the atlas, generally with gentle blunt dissection. Additional lateral exposure is unnecessary and may increase the risk of vertebral artery injury, which courses on the upper superficial portion of the posterior arch of the atlas.

The occipital bone squama and the posterior arch of $\mathrm{C} 1$ are exposed. A laminectomy of the atlas is done using a craniotome or Kerrison's rongeurs. After that, a suboccipital decompression is performed. Our upper limit of the craniectomy is the inferior nuchal line, since this allows for a wide enough craniectomy with enough bone left for the eventual need for future craniocervical stabilization. We prefer to make two burr holes just lateral to the midline at the inferior nuchal line and then perform the craniectomy down to the foramen magnum.

It is of paramount importance to remove the bone of the foramen magnum as far to the lateral as possible, as we believe that this is the most relevant part of bone decompression (Figure 3A). We do not perform total posterior fossa craniectomy (which would include the bone above the inferior nuchal line to the inion), since we believe decompression of the foramen magnum is the actual goal of the surgery. Large craniectomies may hamper reoperation if craniocervical instability develops after Chiari surgery with associated basilar invagination, as the lack of bone may render craniocervical fixation and arthrodesis extremely difficult. Additionally, large craniectomies are associated with cerebellum ptosis, persistent headache and clinical deterioration, requiring reconstruction of the posterior fossa with titanium plates. ${ }^{19}$ 


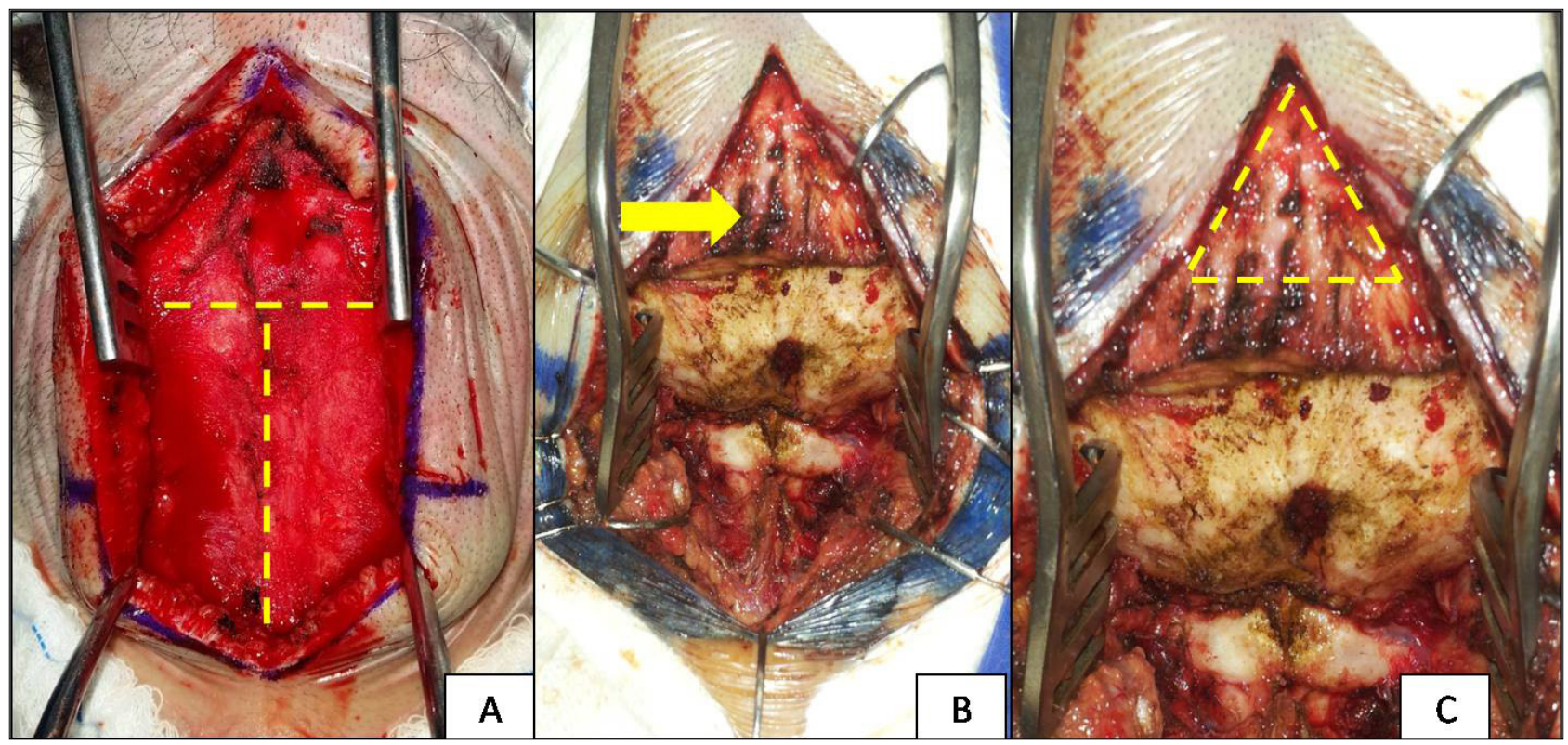

FIGURE 2 A. Exposure of the fascia - the "T" shape illustrates the fascia opening. B. Note the muscle attachment in the superior portion of the incision for suturing the muscles when closuring (yellow arrow). The occipital bone was exposed, as well as the posterior arch of the atlas below. C. The yellow triangle illustrates the site for pericranial harvest for grafting. Note that the muscle inserted in the superior nuchal line is preserved below the grafted area for suturing the paraspinal muscles and the fascia.

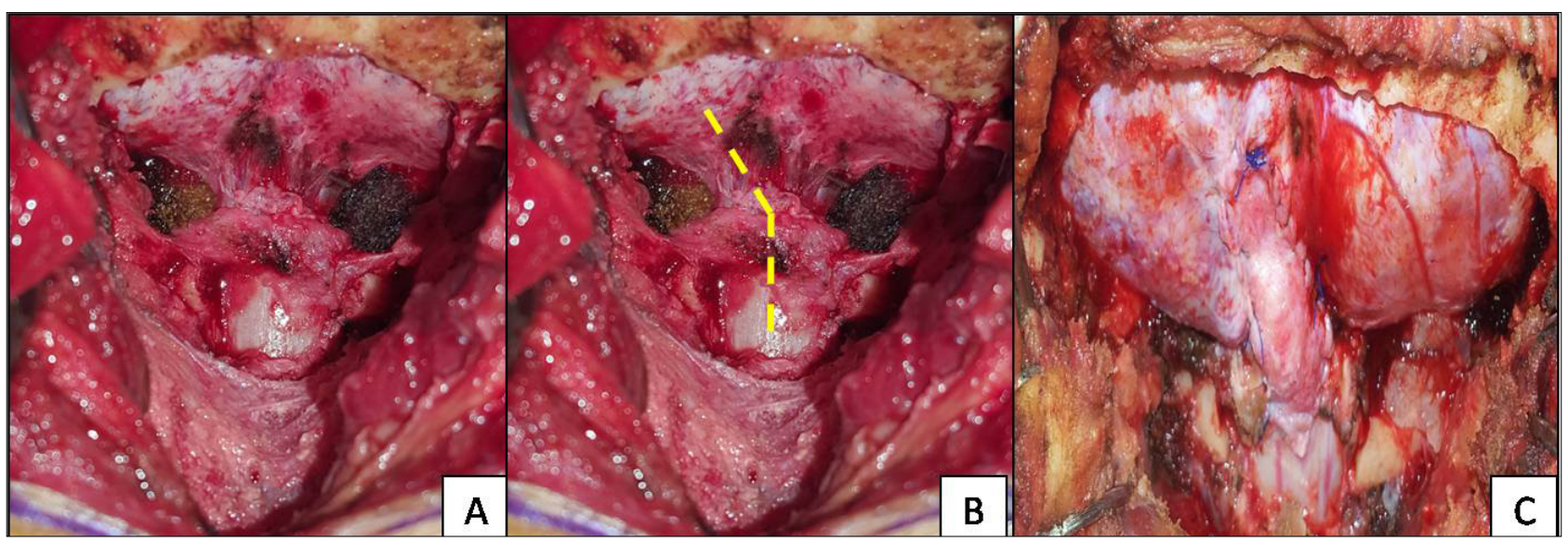

FIGURE 3 A. Posterior fossa craniectomy and removal of the posterior arch of C1. The superior limit of the bone removal is the inferior nuchal line. Laterally, the lateral portions of the foramen magnum were also removed (surgicel was used for bleeding control). Note the muscles still inserted in C2, to preserve their normal function as much as possible. B. We illustrate the dural incision (yellow line). Differently from the "Y" shape traditionally used, this incision allows a more hermetic dural closure after inserting the pericranial graft, decreasing the risks of CSF leak. It starts at the dura mater of the atlas cranially to one of the two sides. C. Final aspect after duraplasty.

\section{Duraplasty and closure}

We perform duraplasty in patients with syringomyelia, important tonsillar herniation (up to $\mathrm{C} 2$ or more than $10 \mathrm{~mm}$ below the level of the foramen magnum) and those with symptoms of neural compression (such as long tract involvement or brainstem compromise). This strategy has also been reported by some authors, such as Gurbuz et al. ${ }^{20}$ For patients with only posterior cervical pain, we prefer to perform bone decompression alone. Although both techniques (with or without duraplasty) are acceptable and result in clinical improvement, the outcome of patients who undergo duraplasty seems slightly better despite the higher risks of complications, such as CSF leak. 
Of note, some authors recommend the use of intraoperative ultrasound for fluid flow assessment in the posterior fossa after bone decompression in order to help decide when to perform the duraplasty. We do not recommend this, since Bond et al. ${ }^{21}$ have reported that, when patients have their necks flexed (positioned for surgery), intraoperative MR demonstrates tremendous improvement in the CSF flow in the foramen magnum dorsal to the tonsils compared to preoperative MRI in prone position. For this reason, we prefer to perform duraplasty using the clinical and radiological criteria previously exposed above.

If we decide to perform duraplasty, instead of the traditional incision in a "Y" shape, we perform a more linear incision as shown in Figure 3B. This type of dural incision allows for a better closure of the dura with the pericranial graft, which decreases the risk of CSF leak. We prefer to use a 5.0 prolene suture, to avoid leak secondary to the other larger needles injury to the dura. We generally do not use any type of glue or dural sealant for primary surgery.

A multilayered closure is then performed. The fascia is sutured in the midline and superiorly to the muscle cushion attached to the superior nuchal line. Simple sutures are preferred to avoid rupture and to maintain a perfect closure. Additional continuous suture may be performed after that. The subcutaneous tissue is then sutured and also fixed to the fascia to avoid the need for postoperative drains and death space. Finally, the skin closure is made with simple sutures.

\section{Conclusion}

When treating patients with Chiari malformation, the proper surgical technique with minute attention to details is extremely important for minimizing the risks of the procedure and to improve the patients' final outcome.

\section{Resumo}

Descompressão de fossa posterior com duroplastia no tratamento cirúrgico do Chiari: nota técnica

A malformação de Chiari (MC) é a malformação craniocervical congênita sintomática mais comum e prevalente. O diagnóstico radiológico é definido quando as tonsilas cerebelares estão localizadas pelo menos $5 \mathrm{~mm}$ abaixo do nível do forame magno na ressonância magnética (RM). Quando há hérnia tonsilar sintomática, siringomielia ou hidrocefalia, o tratamento cirúrgico é indicado. O principal tratamento cirúrgico para MC sem instabilidade craniocervical (como a luxação atlantoaxial) é a descompressão da fossa posterior com ou sem duroplastia. Os autores descrevem detalhadamente a abordagem cirúrgica de pacientes com MC realizada na Universidade Estadual de Campinas, enfatizando nuances técnicas para minimizar os riscos relacionados ao procedimento e melhorar os resultados pós-operatórios.

Palavras-chave: malformação/cirurgia de Arnold-Chiari, cerebelo/patologia, defeitos do tubo neural.

\section{References}

1. Chiari H. Uber Veränderungen des Kleinhirns infolge von Hydrocephalie des Grosshirns. Dtsch Med Wochenshr. 1891; 17:1172-5.

2. Speer MC, George TM, Enterline DS, Franklin A, Wolpert CM, Milhorat TH. A genetic hypothesis for Chiari I malformation with or without syringomyelia. Neurosurg Focus. 2000; 8(3):E12.

3. Goel A. Basilar invagination, Chiari malformation, syringomyelia: a review. Neurol India. 2009; 57(3):235-46.

4. Menezes AH, Traynelis VC. Anatomy and biomechanics of normal craniovertebral junction (a) and biomechanics of stabilization (b). Childs Nerv Syst. 2008; 24(10):1091-100.

5. Smith BW, Strahle J, Bapuraj JR, Muraszko KM, Garton HJ, Maher CO. Distribution of cerebellar tonsil position: implications for understanding Chiari malformation. J Neurosurg. 2013; 119(3):812-9.

6. Batista UC, Joaquim AF, Fernandes YB, Mathias RN, Ghizoni E, Tedeschi $\mathrm{H}$. Computed tomography evaluation of the normal craniocervical junction craniometry in 100 asymptomatic patients. Neurosurg Focus. 2015; 38(4):E5

7. Greitz D. Unraveling the riddle of syringomyelia. Neurosurg Rev. 2006; 29(4):251-63; discussion 264.

8. Oldfield EH, Muraszko K, Shawker TH, Patronas NJ. Pathophysiology of syringomyelia associated with Chiari I malformation of the cerebellar tonsils. Implications for diagnosis and treatment. J Neurosurg. 1994; 80(1):3-15.

9. Zhang Y, Zhang N, Qiu H, Zhou J, Li P, Ren M, et al. An efficacy analysis of posterior fossa decompression techniques in the treatment of Chiari malformation with associated syringomyelia. J Clin Neurosci. 2011; 18(10):1346-9.

10. Bao C, Yang F, Liu L, Wang B, Li D, Gu Y, et al. Surgical treatment of Chiari I malformation complicated with syringomyelia. Exp Ther Med. 2013; 5(1):333-7.

11. Batzdorf U, McArthur DL, Bentson JR. Surgical treatment of Chiari malformation with and without syringomyelia: experience with 177 adult patients. J Neurosurg. 2013; 118(2):232-42.

12. Heiss JD, Suffredini G, Bakhtian KD, Sarntinoranont M, Oldfield EH. Normalization of hindbrain morphology after decompression of Chiari malformation Type I. J Neurosurg. 2012; 117(5):942-6.

13. Logue V, Edwards MR. Syringomyelia and its surgical treatment: an analysis of 75 patients. J Neurol Neurosurg Psychiatry. 1981; 44(4):273-84.

14. Joaquim AF, Ghizoni E, Giacomini LA, Tedeschi H, Patel AA. Basilar invagination: surgical results. J Craniovertebr Junction Spine. 2014; 5(2):78-84.

15. Joaquim AF, Ghizoni E, Almeida JPC, Anderle DV, Tedeschi H. Basilar invagination secondary to hypoplasia of the clivus: is there indication for craniocervical fixation? Coluna/Columna. 2014; 13(1):69-70.

16. Joaquim AF, Fernandes YB, Mathias RN, Batista UC, Ghizoni E, Tedeschi H, et al. Incidence of basilar invagination in patients with tonsillar herniation? A case control craniometrical study. Arq Neuropsiquiatr. 2014; 72(9):706-11.

17. Pritz MB. Surgical treatment of Chiari I malformation: simplified technique and clinical results. Skull Base. 2003; 13(3):173-7.

18. Stevens EA, Powers AK, Sweasey TA, Tatter SB, Ojemann RG. Simplified harvest of autologous pericranium for duraplasty in Chiari malformation Type I. Technical note. J Neurosurg Spine. 2009; 11(1):80-3.

19. Udani V, Holly LT, Chow D, Batzdorf U. Posterior fossa reconstruction using titanium plate for the treatment of cerebellar ptosis after decompression for Chiari malformation. World Neurosurg. 2014; 81(5-6):836-41.

20. Gurbuz MS, Karaaslan N, Caliskan T, Unal E, Berkman MZ. Comparison of the surgical results for foramen magnum decompression with and without duraplasty in Chiari malformation type 1. Turk Neurosurg. 2015; 25(3):419-24.

21. Bond AE, Jane JA Sr, Liu KC, Oldfield EH. Changes in cerebrospinal fluid flow assessed using intraoperative MRI during posterior fossa decompression for Chiari malformation. J Neurosurg. 2015; 122(5):1068-75. 